\title{
Detection of Candidatus Neoehrlichia mikurensis in Norway up to the northern limit of Ixodes ricinus distribution using a novel real time PCR test targeting the groEL gene
}

Andrew Jenkins $^{1 *}$ (D), Cecilie Raasok ${ }^{1,2}$, Benedikte N. Pedersen ${ }^{1}$, Kristine Jensen ${ }^{1,3}$, Åshild Andreassen ${ }^{1,4}$, Arnulf Soleng ${ }^{5}$, Kristin Skarsfjord Edgar ${ }^{5}$, Heidi Heggen Lindstedt ${ }^{5}$, Vivian Kjelland ${ }^{6,7}$, Snorre Stuen ${ }^{8}$, Dag Hvidsten ${ }^{9}$ and Bjørn-Erik Kristiansen ${ }^{10}$

\begin{abstract}
Background: Candidatus Neoehrlichia mikurensis is an emerging tick-borne pathogen. It is widely distributed in Ixodes ricinus ticks in Europe, but knowledge of its distribution in Norway, where I. ricinus reaches its northern limit, is limited. In this study we have developed a real time PCR test for $C a$. N. mikurensis and used it to investigate the distribution of $\mathrm{Ca}$. N. mikurensis in Norway.

Results: Real time PCR targeting the groEL gene was developed and shown to be highly sensitive. It was used to detect $\mathrm{Ca}$. N. mikurensis in 1651 I. ricinus nymphs and adults collected from twelve locations in Norway, from the eastern Oslo Fjord in the south to near the Arctic Circle in the north. The overall prevalence was $6.5 \%$ and varied locally between 0 and $16 \%$. Prevalence in adults and nymphs was similar, suggesting that ticks acquire $\mathrm{Ca}$. N. mikurensis predominantly during their first blood meal. In addition, 123 larvae were investigated; Ca. N. mikurensis was not found in larvae, suggesting that transovarial transmission is rare or absent. Sequence analysis suggests that a single variant dominates in Norway.
\end{abstract}

Conclusions: Ca. N. mikurensis is widespread and common in ticks in Norway and reaches up to their northern limit near the Arctic Circle. Ticks appear to acquire Ca. N. mikurensis during their first blood meal. No evidence for transovarial transmission was found.

Keywords: Neoehrlichia mikurensis, Ixodes ricinus, Ticks, Tick-borne diseases, Norway, Scandinavia

\section{Introduction}

Candidatus Neoehrlichia mikurensis (Ca. N. mikurensis) is an emerging tick-borne pathogen belonging to the order Rickettsiales, family Anaplasmataceae. Sequences corresponding to $\mathrm{Ca}$. N. mikurensis were detected as early as 1999 in the Netherlands [1] and in 2001 in Norway [2] but their taxonomic position was not resolved; they were referred to informally as 'Ehrlichia-like organism' or 'E.

\footnotetext{
* Correspondence: andrew.jenkins@usn.no

${ }^{1}$ Department of Natural Science and Environmental Health, University of

South-Eastern Norway, Bø, Norway

Full list of author information is available at the end of the article
}

schotti' although taxonomy of the genus Ehrlichia was at that time also unresolved.

The organism itself was first described in 2004 by Kawahara et al. [3] in rats (Rattus norvegicus) and Ixodes ovatus ticks from the Japanese island of Mikura. Sequence analyses showed that it was a new species within the recently reorganized [4] family Anaplasmataceae but that it did not belong to any of the existing genera. A new candidate genus, 'Neoehrlichia' was proposed to accommodate it and the name Candidatus Neoehrlichia mikurensis was proposed [3]. The first cases of human infection were reported from Sweden and Germany in 
2010 [5, 6]. Neoehrlichiosis is primarily a disease of immunocompromised patients, who experience recurring fevers accompanied by a variety of other manifestations including musculoskeletal pain and deep-vein thrombosis [7]. Infections in immunocompetent persons may result in low-grade fever [8] or be asymptomatic [9]. Symptoms usually resolve quickly after treatment with tetracycline [7].

$\mathrm{Ca}$. N. mikurensis appears to have a pan-Eurasian distribution, from Japan and China in the east $[3,8]$ to Spain in the west [10] and it has been found in all but one (Poland) of the 15 mainland European countries investigated so far [10-18]. In Western Europe, the tick host is I. ricinus, while in Russia it is I. persulcatus [19] and in Japan it is I. ovatus [3]. The main mammalian reservoir hosts for $\mathrm{Ca}$. N. mikurensis appear to be wild rodents, including rats (Rattus norvegicus) [3], voles and mice [20-23]. Rodents are able to transmit Ca. N. mikurensis to xenodiagnostic ticks [22] and infection is widespread and common [17, 20-23]. There is also strong evidence for transplacental transmission in rodents [21]. Infections have also been detected in dogs [24] and hedgehogs [25], but not in shrews, moles or foxes [11, 19, 20, 23, 26].

Although $\mathrm{C} a$. N. mikurensis can be visualized by electron microscopy [3] and morulae may be detected in infected cells [9], the vast majority of studies have employed PCR-based methods. In earlier studies, detection was by $16 \mathrm{~S}$ rDNA PCR followed by DNA hybridization $[1,2]$ or DNA sequencing [5] but more recently quantitative real time PCR (qPCR) tests targeting the $16 \mathrm{~S}$ rDNA or groEL genes [11, 12, 27] have been applied. The latter methods are rapid, quantitative and less prone to contamination. Structural genes, such as groEL, have the advantage that they contain little secondary structure and it is easier to achieve specificity.

In this study, we describe the development and evaluation of a new real time PCR assay targeting the groEL gene of $\mathrm{Ca}$. N. mikurensis and its use to determine the prevalence of $\mathrm{Ca}$. N. mikurensis in I. ricinus ticks at localities throughout their northernmost habitat, the coastal regions of Norway, from the Oslo Fjord in the Southeast to the Arctic Circle in the North [28-31]. We also addressed the question of transovarial transmission of $C a$. N. mikurensis by investigating a collection of $I$. ricinus larvae from a high-prevalence area.

\section{Materials and methods}

\section{Tick collections and DNA extraction}

Ticks were collected from vegetation by flag-dragging [32] or from dogs and cats brought to veterinary clinics [33]. DNA was extracted by (1) manual disruption and protease digestion [2], (2) mechanical disruption, automated total nucleic acid extraction and reverse transcription of total nucleic acid [33], (3) digestion with ammonium hydroxide $[34,35]$ or (4) phenol-chloroform extraction [36]. Table 1 describes the tick collections, the instar distribution and the method used for DNA extraction.

\section{Design of PCR}

Our aim was to establish a real time PCR test that could be used either as a TaqMan PCR, with the extra specificity that the TaqMan probe potentially offers, or as a SYBR-green PCR, with the possibility of detecting sequence variants using standard single-derivative melting curves. A survey of $C a$. N. mikurensis sequences available in April 2012 indicated that the groEL gene, which codes for a highly conserved heatshock protein [41], was a promising candidate for primer design. All available Ca. N. mikurensis groEL genes per 17.04.2012, together with groEL genes of Candidatus Neoehrlichia lotoris, Ehrlichia muris, E. chafeensis, E. canis, E. ruminantium, E. ewingii, $C a$. E. shimanensis and unclassified Ehrlichia spp., were aligned using CLUSTALW; the alignments were displayed using BOXSHADE in order to identify sequence regions conserved within $\mathrm{Ca}$. N. mikurensis but differing in other taxa. In order to select efficient primers, PrimerExpress v. 2.0 (Applied Biosystems, Foster City, CA, USA) was run, using $C a$. N. mikurensis GroEL sequence $A B 084583$ as the input sequence and program settings for design of TaqMan MGB $^{\text {Ta }}$ real time PCR. The output primer and probe sequences were then compared with the multiple sequence alignment in order to identify sequences targeting suitable regions. This resulted in the selection of a probe and primers targeting the region 560-688 in AB084583. Figure 1 shows the sequence alignment and the positions of the primers and the probe. The primer and probe sequences were:

Forward Primer, Neo2f: GCAAATGGAGATAAAAAC ATAGGTAGTAAA.

Reverse Primer, Neo2r: CATACCGTCAGTTTTTTCA ACTTCTAA.

Probe, Neo2m: TTACAGTTGAGGAAAGTAAGGGA (TaqMan MGB $^{\text {ma }}$ probe labelled with FAM (5(6)-carboxyfluorescein).

\section{Controls}

In order to provide a quantifiable positive control, a synthetic plasmid, pNeo, was constructed according to our specifications (GenScript, Piscataway, NJ). pNeo is vector pUC57 with a de novo synthesized insert corresponding to positions 550-690 in sequence AB094461 (strain IS58). pNeo contains the $129 \mathrm{bp}$ PCR target sequence plus $6 \mathrm{bp}$ of flanking sequence on each side. AB094461 is the $C a$. N. mikurensis groEL sequence with the greatest degree of divergence from the primer and probe sequences and was 
Table 1 Overview of tick collections

\begin{tabular}{|c|c|c|c|c|c|c|c|c|c|}
\hline Location & Name $^{1}$ & Date (yyyy or yy-mm) & Larvae & Nymphs & Adults & Total & Source & Extraction method & Reference \\
\hline 1 & Spjærøya (ØS) & $12-09$ & - & 67 & - & 67 & Flagging & 4 & {$[37]$} \\
\hline 2 & На̊øуа (AK) & $13-05$ & - & 95 & - & 95 & Flagging & 4 & [37] \\
\hline 3 & Brønnøya (AK) & $13-06$ & - & 92 & - & 92 & Flagging & 4 & [37] \\
\hline \multirow[t]{5}{*}{4} & Langøya (TE) & 00-04 & 63 & - & - & & Flagging & 1 & This work \\
\hline & & 00-05 & 15 & - & - & & Flagging & 1 & This work \\
\hline & & $00-06$ & 25 & - & - & & Flagging & 1 & This work \\
\hline & & $00-07$ & 20 & - & - & & Flagging & 1 & This work \\
\hline & & All dates & 123 & - & - & 123 & & & \\
\hline \multirow[t]{6}{*}{5} & Langøya (TE) & 00-05 & - & 47 & 25 & 72 & Flagging & 3 & This work \\
\hline & & $00-06$ & - & 9 & 13 & 22 & Flagging & 3 & This work \\
\hline & & $01-05$ & - & 1 & 26 & 27 & Flagging & 3 & This work, [38] \\
\hline & & $02-05$ & - & 24 & 24 & 48 & Flagging & 3 & This work, [38] \\
\hline & & 03-05 & - & 25 & - & 25 & Flagging & 3 & This work, [38] \\
\hline & & All dates & & 106 & 88 & 194 & & & \\
\hline 6 & Jomfruland (TE) & $12-09$ & - & 495 & - & - & Flagging & 1 & [39] \\
\hline 7 & Lower Telemark (TE) & 2009 & - & - & 103 & 103 & Dogs and cats & 2 & [33] \\
\hline 8 & Tromøya (AA) & $12-06$ & - & 95 & - & 95 & Flagging & 4 & [37] \\
\hline 9 & Hillevågen (VA) & $12-06$ & - & 80 & - & 80 & Flagging & 4 & [37] \\
\hline 10 & Reme (VA) & $00-07$ & - & 48 & 51 & 99 & Flagging & 3 & This work, [40] \\
\hline 11 & Vindafjord (RO) & $00-07$ & - & 24 & 5 & 29 & Flagging & 3 & This work, [40] \\
\hline 12 & Stord/Borgundøy (HO) & $00-07$ & - & 26 & 47 & 73 & Flagging & 3 & This work, [40] \\
\hline 13 & Northern Norway (NO, TR) & 2009 & - & - & 139 & 139 & Dogs and cats & 2 & [33] \\
\hline
\end{tabular}

${ }^{1}$ Two-letter code in brackets indicates the county: ØS (Østfold); AK (Akershus); TE (Telemark); AA (Aust Agder); VA (Vest Agder); RO (Rogaland); HO (Hordaland); NO (Nordland); TR (Troms)

chosen in order to ensure a conservative estimate of PCR efficiency and sensitivity. Tenfold serial dilutions of pNeo from $1.6 \times 10^{9}$ to $1.6 \times 10^{0}$ copies per $5 \mu$ aliquot were prepared and used in the determination of analytical sensitivity and PCR efficiency, optimization of primer and probe concentrations and standard curves for quantification of $\mathrm{Ca}$. $\mathrm{N}$. mikurensis in ticks. Alternatively, in some PCR runs, two tick samples containing an estimated $3 \times 10^{3}$ and $6 \times 10^{4}$ GU per reaction respectively were used as positive controls. These control samples were positive by the reverse line blot test and have been described in a previous study [2]. For evaluation of sensitivity and specificity, 38 tick samples from the latter study that had been analysed by the reverse line blot test were used. Samples for cross-reaction testing were four tick samples containing Midichloria mitochondrii (source: reference [2]), one tick sample containing Wolbachia (source: reference [2]), DNA from cultured Ehrlichia chaffeensis and E. muris, DNA from blood of an E. canis infected dog, DNA from blood of an Anaplasma phagocytophilum infected horse and DNA from blood of an $A$. phagocytophilum infected sheep. Control DNA was stored at $-20^{\circ} \mathrm{C}$ when not in use; repeated freeze-thaw cycles were avoided.

\section{PCR}

Real time PCR was run on the Applied Biosystems StepOne (Applied Biosystems, Foster City, CA, USA) using Applied Biosystems SYBR-green mastermix and primers Neo2f/Neo2r or TaqMan mastermix, the same primers, plus probe $\mathrm{Neo} 2 \mathrm{~m}$ as required. Primers were obtained from Applied Biosystems, Foster City, CA, USA or Integrated DNA Technologies, Leuven, Belgium. Except where otherwise stated, the SYBR-green PCR was used. The reaction volume was $25 \mu \mathrm{l}$, including $5 \mu \mathrm{l}$ of template DNA, corresponding to $90 \pm 60 \mathrm{ng}$ for extraction methods 1 and 4 and $17 \pm 10 \mathrm{ng}$ for methods 2 and 3. Two positive controls (pNeo, $16 \mathrm{GU}, 1.6 \mathrm{GU}$, or two positive tick samples containing an estimated $3 \times 10^{3}$ and $6 \times 10^{4} \mathrm{GU}$ respectively), plus two negative controls (no DNA added) were included in each run of 48 samples. The PCR program was $50^{\circ} \mathrm{C}, 2 \mathrm{~min} ; 95^{\circ} \mathrm{C}, 10 \mathrm{~min}$, $\left\{95^{\circ} \mathrm{C}, 15 \mathrm{~s} ; 60^{\circ} \mathrm{C}, 1 \mathrm{~min}\right\} \times 45$ cycles. For runs using SYBR-green, dissociation analysis $\left(60^{\circ} \mathrm{C}\right.$ to $95^{\circ} \mathrm{C}$ with $0.3^{\circ} \mathrm{C}$ increments) was appended to the program. Background subtraction, threshold setting, and the determination of $\mathrm{Cq}, \mathrm{Tm}$, and PCR efficiency were performed automatically by the instrument software (StepOne ${ }^{\circ}$ and 

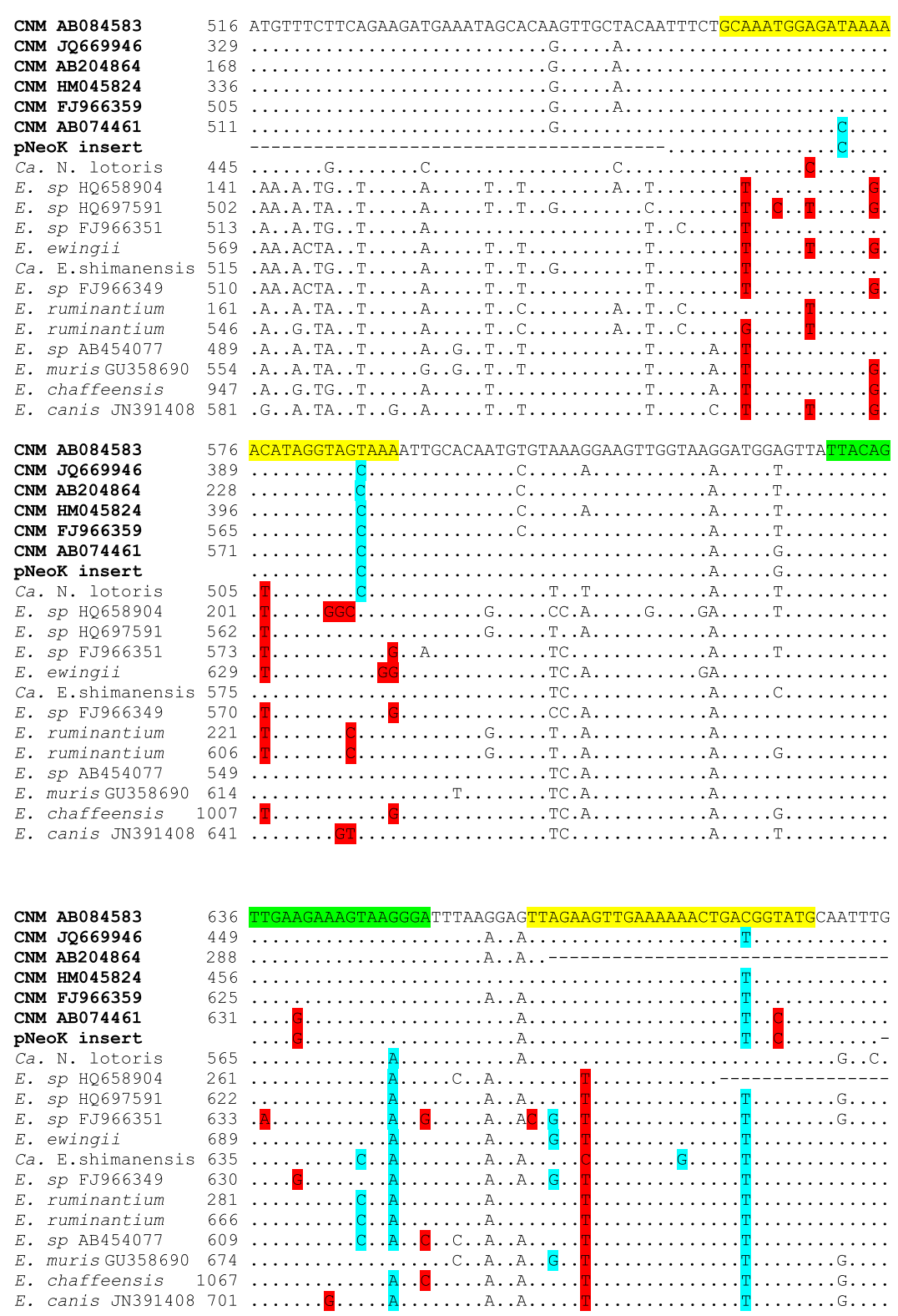

Fig. 1 Multiple sequence alignment of the PCR target regions of groEL in Ca. N. mikurensis (CNM), Ca. N. lotori and selected Ehrlichia species. Dots indicate identity to the reference sequence, AB084583; letters indicate differences; hyphens indicate gaps or no sequence. The target regions for the primers and probe are highlighted in yellow and green respectively. Mismatches within the primer/probe target regions that give stable G:T basepairs are highlighted in blue. Destabilising mismatches (variants resulting in A:C, purine:purine or pyrimidine:pyrimidine) are highlighted in red. For reasons of space, sequence accession numbers for $\mathrm{Ca}$. N. lotoris, Ehrlichia ewingii, Candidatus E. shimanensis, two sequence variants of E. ruminantium and E. chafeensis have been omitted from the figure; these are: EF633745, AF195273, AB074462, AB625796, DQ647005 and JQ085941 respectively

StepOnePlus ${ }^{\circ}$ Real-Time PCR System Software Version 2.3); all instrument data was examined visually and manual corrections to threshold and background were made when necessary. Samples were considered positive if they displayed a detectable amplification curve rising above threshold on a logarithmic plot of fluorescence and a distinct melting peak at a temperature $(\mathrm{Tm})$ between $71.7^{\circ} \mathrm{C}$ and $75^{\circ} \mathrm{C}$. Where sufficient material was available, the TaqMan probe PCR was used to confirm positive results.

\section{DNA sequencing}

The PCR products were purified using ExoSAP-IT (Applied Biosystems, Foster City, CA, USA) according to the manufacturer's instructions. BigDye Terminator v1.1 Cycle Sequencing Kit (Applied Biosystems, Foster City, 
CA, USA) was used to sequence PCR products directly in both forward and reverse direction, using primers Neo2r and Neo2f (sources as for PCR) on a 3130 Genetic Analyzer automated capillary sequencer (Applied Biosystems, Foster City, CA). The sequencing reactions were prepared and purified by ethanol precipitation according to the manufacturer's instructions.

Forward and reverse sequences were assembled and edited using Chromas Pro v. 2.1.6 (Technelysium, Brisbane, Australia) and controlled by visual examination of the chromatograms. After trimming off the primer sequences, sequences were identified by BLAST search.

\section{Statistical methods}

The 95\% confidence intervals for prevalence estimates were calculated using the formulae:

$$
P_{L}=\frac{\left(2 n p+z_{\alpha / 2}^{2}-1\right)-z_{\alpha / 2} \cdot \sqrt{z_{\alpha / 2}^{2}-\{2+(1 / n)\}+4 p(n q+1)}}{2\left(n+z_{\alpha / 2}^{2}\right)}
$$

and

$$
P_{U}=\frac{\left(2 n p+z_{\alpha / 2}^{2}+1\right)+z_{\alpha / 2} \cdot \sqrt{z_{\alpha / 2}^{2}+\{2-(1 / n)\}+4 p(n q-1)}}{2\left(n+z_{\alpha / 2}^{2}\right)}
$$

for the lower and upper confidence limits respectively, where $\mathrm{n}$ is the number of samples, $\mathrm{p}$ and $\mathrm{q}$ are the proportions of positive and negative samples and $z_{\alpha / 2}$ is the critical value of the normal distribution for $\alpha / 2$, in this case 1.96 [42]. The confidence limits are not valid if $\mathrm{p}$ or $\mathrm{q} \leq 5 / \mathrm{n}$; in such cases, no confidence interval was reported, except in the case of zero observed prevalence, where the upper $95 \%$ confidence limit may be calculated as $P_{U}=1-\sqrt[N]{0.05}$.

For significance testing the $\chi^{2}$ test was applied using Microsoft Excel.

\section{Results}

\section{In silico assessment of the PCR test}

Figure 1 shows that the primer and probe target sequences are somewhat variable among $C a$. N. mikurensis strains, containing up to two mismatches to either primer or one mismatch to the probe. In all but one case, these are transition mutations that will allow the formation of a G:T base pair, which is nearly as stable as the canonical A:T. In one sequence, variants at the probe and reverse primer targets will result in destabilizing C:A mismatches. We deliberately chose this sequence as the insert in the positive control plasmid in order to provide the most stringent possible control of analytical sensitivity.
The most closely related species, Ca. Neoehrlichia lotoris and Ehrlichia spp., have at least two destabilizing mismatches in the forward primer target, together with smaller numbers of mismatches in the probe and reverse primer regions.

\section{Optimization of PCR}

Forward and reverse primer concentrations of 100 , 200, 400 and $800 \mathrm{nM}$ were tested in all combinations. The effect of primer concentration on $\mathrm{Cq}$ values was slight. A primer concentration of $800 \mathrm{nM}$ was chosen for all subsequent experiments. Probe concentrations of 50,100, 200, 400, 800 and $1600 \mathrm{nM}$ were tested; signal strength increased up to $200 \mathrm{nM}$; no improvement was found at higher probe concentrations.

\section{Comparison of SYBR-green and TaqMan modalities}

Figure 2 shows a comparison of amplification of a serial dilution of a positive control sample using SYBR-green and the TaqMan MGB probe respectively. While the detection limit (between sample dilutions of 1:500 and 1: 2500 ) is the same for both modalities, SYBR-green gave $\mathrm{Cq}$ values that were $6.5-7$ cycles lower and plateau signals that were approximately 20x higher, possibly as a result of intrinsic differences in fluorescence signal strength caused by fluorophor stoichiometry. As SYBRgreen PCR gave stronger signals and the additional information of a Tm value for the amplicon, with the potential for detecting sequence variants, it was chosen for primary analysis of all samples.

\section{Efficiency and analytical sensitivity}

PCR efficiency, estimated from a standard curve (Fig. 3) derived from a triplicate run of a dilution series of pNeo from $1.6 \times 10^{9}$ to 1.6 copies/reaction, was $95 \%$. The standard curve was linear $\left(R^{2}=0.999\right)$ throughout the range. All of three samples containing 1.6 copies/reaction were positive.

\section{Comparison with the reverse line-blot test}

Thirty-eight ticks previously tested using the reverse line-blot test $[1,2]$ were tested with the current real time PCR test. Results are shown in Table 2. Relative to reverse line-blot, real time PCR showed $100 \%$ sensitivity. However, an additional four samples were positive with the real time PCR test. These four samples all showed very high $\mathrm{Cq}$ and/or anomalous $\mathrm{Tm}$ values.

\section{Specificity}

In order to test for cross-reaction with other members of the Rickettsiales, the current real time PCR test was run on samples containing Anaplasma phagocytophilum $(N=2)$, Midichloria mitochondrii $(N=$ 


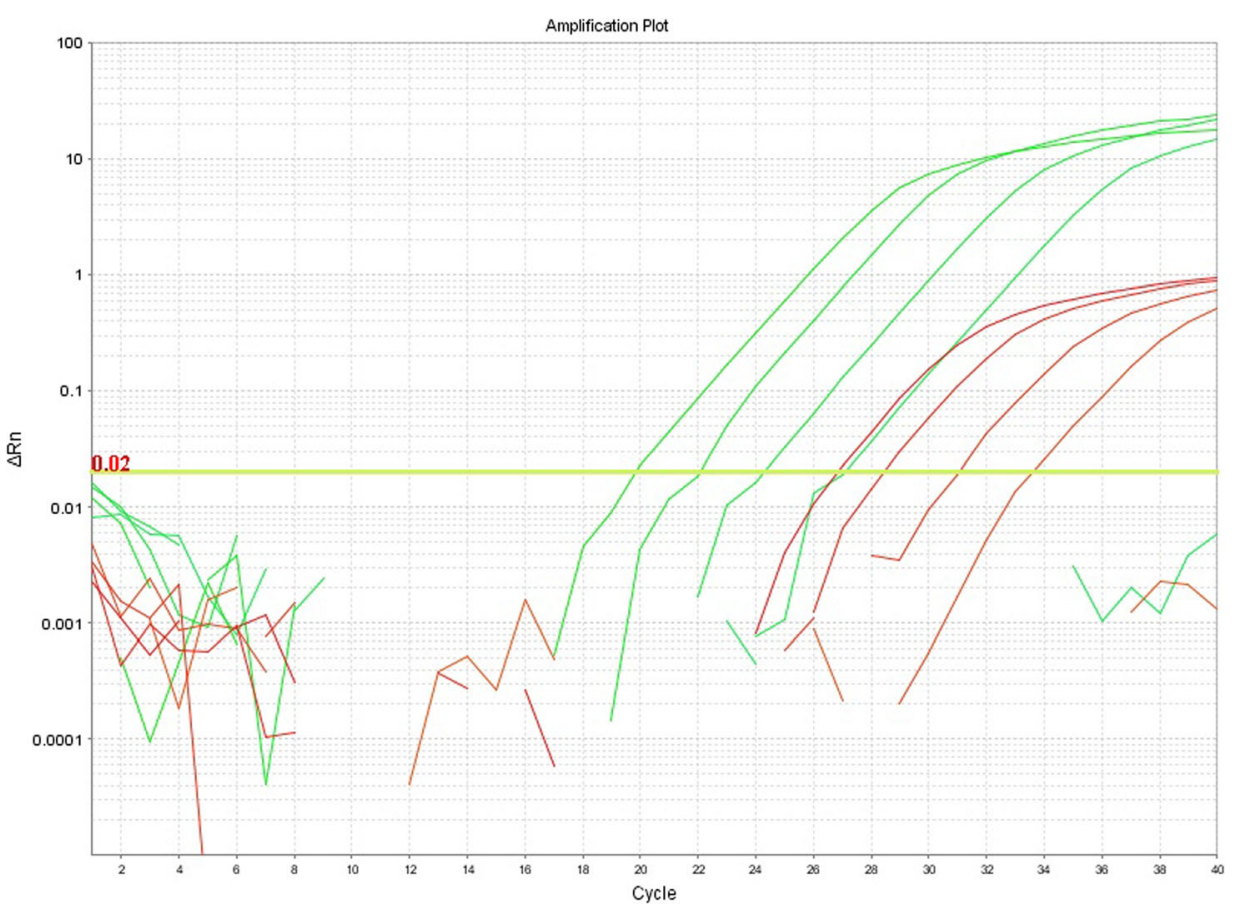

Fig. 2 Comparison of TagMan MGB Probe and SYBR green PCR. Amplification of a dilution series of an I. ricinus sample positive for Ca. N. mikurensis. Dilutions are 1:4, 1:20, 1:100, 1:500 and 1:2500 respectively. Green curves are for SYBR-green, red curves are for TaqMan MGB probe. The signals to the lower right of the amplification curves below the yellow-green threshold line are background noise from the 1:2500 dilutions

4), Wolbachia $(N=1)$, Ehrlichia canis $(N=1)$, Ehrlichia chaffeensis $(N=1)$ and Ehrlichia muris $(N=1)$. Both E. chaffeensis and E. muris gave positive results; Tm was 73.9 for E. chaffeensis and 76.1 for E. muris; neither was positive with the TaqMan MGB probe. One of the four samples containing $M$. mitochondrii gave a very weak positive signal $(\mathrm{Cq}=45)$ with a bimodal melting curve $(\mathrm{Tm}=72.4,74.9)$. All other samples were negative.

\section{Prevalence of $\mathrm{Ca}$. N. Mikurensis in ticks}

Table 3 and Fig. 4 show the prevalence of $\mathrm{Ca}$. N. mikurensis in nymphal and adult ticks in the various collections based on SYBR-green PCR. The overall prevalence was $6.5 \%$, and varied between zero and $16 \%$ at different localities. Cq values varied between 21 and $45 ; 3.7 \%$ of values were $<25 ; 89.8 \%$ were in the range $25-40$ and $6.5 \%$ were $>40$.

All three tick collections with zero prevalence were collected in August 2000 at locations in the southern part of the western seaboard.

There was no significant difference in $\mathrm{Ca}$. N. mikurensis prevalence between nymphs and adults or between males and females.

In order to investigate the possibility of PCR inhibition distorting our prevalence estimates, negative samples extracted using each of the four different extraction methods were spiked with $1000 \mathrm{GU}$ of a $\mathrm{Ca}$.
N. mikurensis-positive sample and retested. Samples were considered partially inhibitory if they had an increased $\mathrm{Cq}$ value, completely inhibitory if no PCR signal was seen, and non-inhibitory if $\mathrm{Cq}$ was unchanged relative to a spiked aliquot of water. The results are shown in Table 4. The percentage of inhibitory samples was low with samples extracted with methods 1 and 3 (which includes the three zero-prevalence collections), while samples extracted with methods 2 and 4 had a high percentage of partial or complete inhibition. Thus, the prevalence estimates for collections 1 , $2,3,7,8,9$ and 13 must be considered lower bounds for the true prevalence.

\section{Larvae}

Larvae $(N=123)$ were analysed in pools of $5-9$. None of the pools were positive. The same pools were then spiked with 1600 copies of pNeo and reanalysed. All pools were positive after spiking, indicating that these are true negative results and not the consequence of PCR inhibition. These larvae were collected in April June 2000. In the previous year, the prevalence in female ticks at the same location was $8 \%$ [2].

Tm variations, sequencing and confirmation by TaqMan MGB probe

SYBR-green PCR dissociation analysis gave amplicon Tm values varying between 71.7 and 74.5 , with all but 


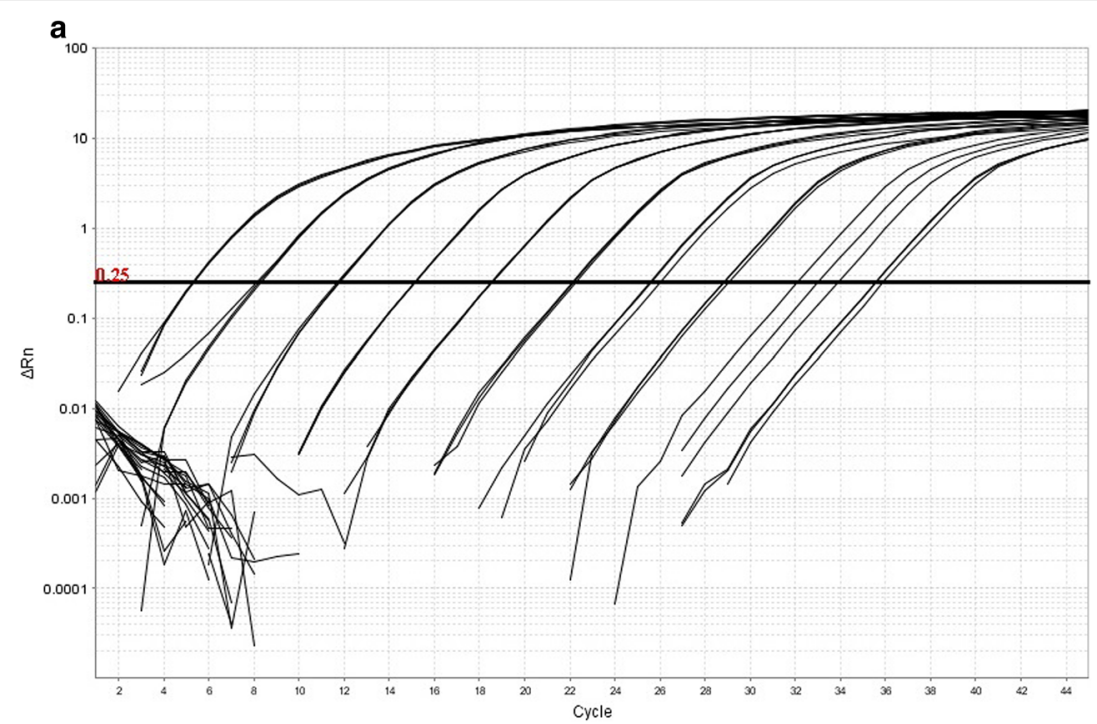

b

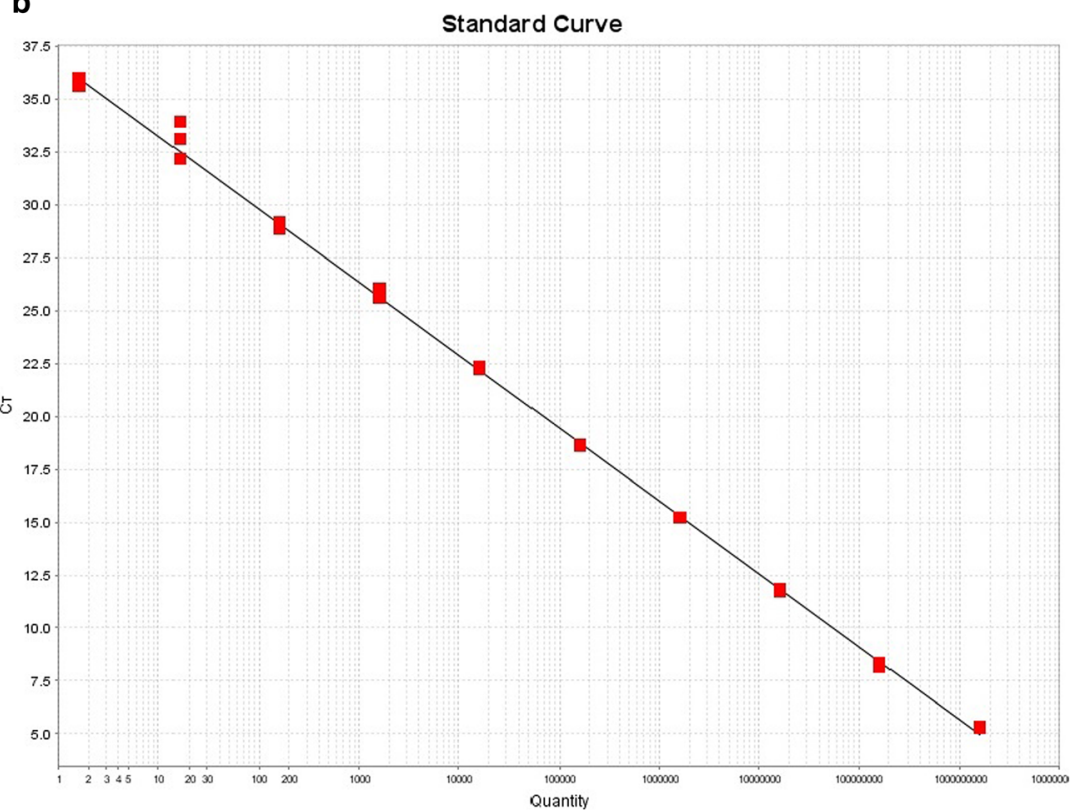

Fig. 3 a Amplification curves for a 10x dilution series of pNeo containing from $1.6 \times 10^{9}$ copies (leftmost curves) to $1.6 \times 10^{0}$ copies (rightmost curves). b Standard curve of Cq values (CT) derived from (a) plotted against number of copies of the groEL gene (quantity; logarithmic scale)

Table 2 Comparison of the reverse line-blot (RLB) and groEL SYBR-green real time PCR methods for detection of Ca. N. mikurensis

\begin{tabular}{lccc}
\hline & & \multicolumn{2}{c}{ Real time PCR } \\
\cline { 3 - 4 } & & Pos & Neg \\
\hline RLB & Pos & 12 & 0 \\
& Neg & 4 & 22 \\
\hline
\end{tabular}

five samples in the range 72.2-74.2. Values for the plasmid control and the tick sample controls were 74.2 \pm 0.5 and $73.4 \pm 0.5$ respectively. This, combined with the observed cross-reaction with Ehrlichia species suggested sequence variation in the amplicon and/or cross-reaction with other species. It was therefore considered desirable to confirm positive results using the TaqMan MGB probe $\mathrm{Neo} 2 \mathrm{~m}$ and/or by sequencing. Sixty-five SYBR-green positive samples were available for retesting. In all, 62/65 samples from eight locations were confirmed using the probe PCR, while 15/15 samples that generated readable sequence were confirmed as $\mathrm{Ca}$. N. mikurensis by BLAST 
Table 3 Proportions of ticks positive for $\mathrm{Ca}$. N. mikurensis

\begin{tabular}{|c|c|c|c|c|c|c|c|}
\hline Collection & Location & Larvae & Nymphs & Males & Females & Total & $\%(C \mathrm{Cl})^{\mathrm{a}}$ \\
\hline 1 & Spjærøy & - & $7 / 67$ & - & - & $7 / 67$ & $10(5-21)$ \\
\hline 2 & На̊øуа & - & $5 / 95$ & - & - & $5 / 95$ & 50 \\
\hline 3 & Brønnøya & - & $11 / 92$ & - & - & $11 / 92$ & $12(6-21)$ \\
\hline 4 & Langøya & $0 / 123$ & - & - & - & $0 / 123$ & $0(0-2.4)$ \\
\hline \multirow[t]{4}{*}{5} & Langøya & - & $23 / 106$ & - & - & - & $22(15-31)$ \\
\hline & & - & - & $7 / 48$ & - & - & $15(7-28)$ \\
\hline & & - & - & - & $2 / 40$ & - & 50 \\
\hline & & & & & & $32 / 194$ & $16(12-23)$ \\
\hline 6 & Jomfruland & - & 23/495 & - & - & $23 / 495$ & $5(3-7)$ \\
\hline 7 & Lower Telemark & - & - & - & $5 / 103$ & $5 / 103$ & 50 \\
\hline 8 & Tromøya & - & 9/95 & - & - & 9/95 & $9(5-18)$ \\
\hline 9 & Hillevåg & - & $13 / 80$ & - & - & $13 / 80$ & $16(9-27)$ \\
\hline 10 & Reme & - & $0 / 48$ & $0 / 25$ & $0 / 26$ & $0 / 101$ & $0(0-2.9)$ \\
\hline 11 & Vindafjord & - & $0 / 24$ & $0 / 4$ & $0 / 1$ & $0 / 29$ & $0(0-10)$ \\
\hline 12 & Stord & - & $0 / 25$ & $0 / 22$ & $0 / 26$ & $0 / 73$ & $0(0-4)$ \\
\hline 13 & Nordland & - & - & - & 9/139 & 9/139 & $6(3-12)$ \\
\hline All nymphs & & & $79 / 1127$ & - & - & - & $7(6-9)$ \\
\hline All males & & & & 7/99 & & & $7(3-15)$ \\
\hline All females & & & & & $16 / 335$ & & $5(3-8)$ \\
\hline All adults & & & & & & $23 / 434$ & $5(3-8)$ \\
\hline All ticks ${ }^{b}$ & & & & & & $102 / 1561$ & $6.5(5.2-7.8)$ \\
\hline
\end{tabular}

${ }^{\mathrm{a}} 95 \%$ confidence interval in brackets. Where confidence intervals could not be calculated, this is indicated by empty brackets. ${ }^{\mathrm{b}}$ Excluding larvae

search (Table 5). All sequences were identical to the $C a$. N. mikurensis sequence JQ669946. These samples had Tm values ranging from 72.2 to 74.1 .

\section{Discussion}

In this study we have developed a new real time PCR test targeting the groEL gene of $\mathrm{Ca}$. N. mikurensis. The test is highly sensitive, with samples containing as little as 1.6 DNA copies per $5 \mu \mathrm{l}$ aliquot giving repeatably positive results. 12/12 samples in which $C a$. N. mikurensis had previously been detected by reverse line-blot $[1,2]$ were also positive in the current PCR test, despite having been stored for more than 15 years.

The PCR may be run either with a TaqMan MGB ${ }^{\text {ma }}$ probe or with SYBR-green combined with dissociation analysis. The analytical sensitivity is similar in either case. In this study we chose SYBR-green PCR as the primary test as it gave stronger signals and lower $\mathrm{Cq}$ values, and as we wished to investigate the possibility of using $\mathrm{Tm}$ analysis to detect sequence variants. A stronger signal is expected with SYBR-green, as each amplicon may bind multiple SYBR-green molecules, while for a TaqMan assay, only one probe fluorophore molecule is released from quenching per amplicon synthesized.
Although the amplicon Tm measured varied from 71.7 to $74.5^{\circ} \mathrm{C}$, this appears to be due to variations in experimental conditions or sample quality, as all amplicons sequenced (Tm range $72.2-74.1^{\circ} \mathrm{C}$ ) were identical to sequence JQ669946 and as large Tm deviations mostly disappeared after dilution of the sample (data not shown). The difference in $\mathrm{Tm}$ between sequences of the JQ669946 type present in samples $\left(73.4^{\circ} \mathrm{C}\right)$ and the AB094461 present in the positive control plasmid $\left(74.2^{\circ} \mathrm{C}\right)$ could be detected.

No cross-reaction with Anaplasma phagocytophilum, Wolbachia or Ehrlichia canis was observed. However, E. chaffeensis and $E$. muris gave significant cross-reaction. Both species have multiple mismatches to both primers, but these are well-removed from the 3 ' end. Although Fig. 2 indicates a destabilising mismatch at the $3^{\prime}$ end of the forward primer in E. chaffeensis (which would preclude amplification), this position is variable, with some sequences allowing formation of a canonical A:T base pair; we assume that it is such a variant that we have tested. A weak cross-reaction occurred with one of four samples containing Midichloria mitochondrii. A BLAST search of $M$. mitochondrii groEL sequences indicated eight mismatches with the forward primer and failed to detect any homology with the reverse primer sequence. 


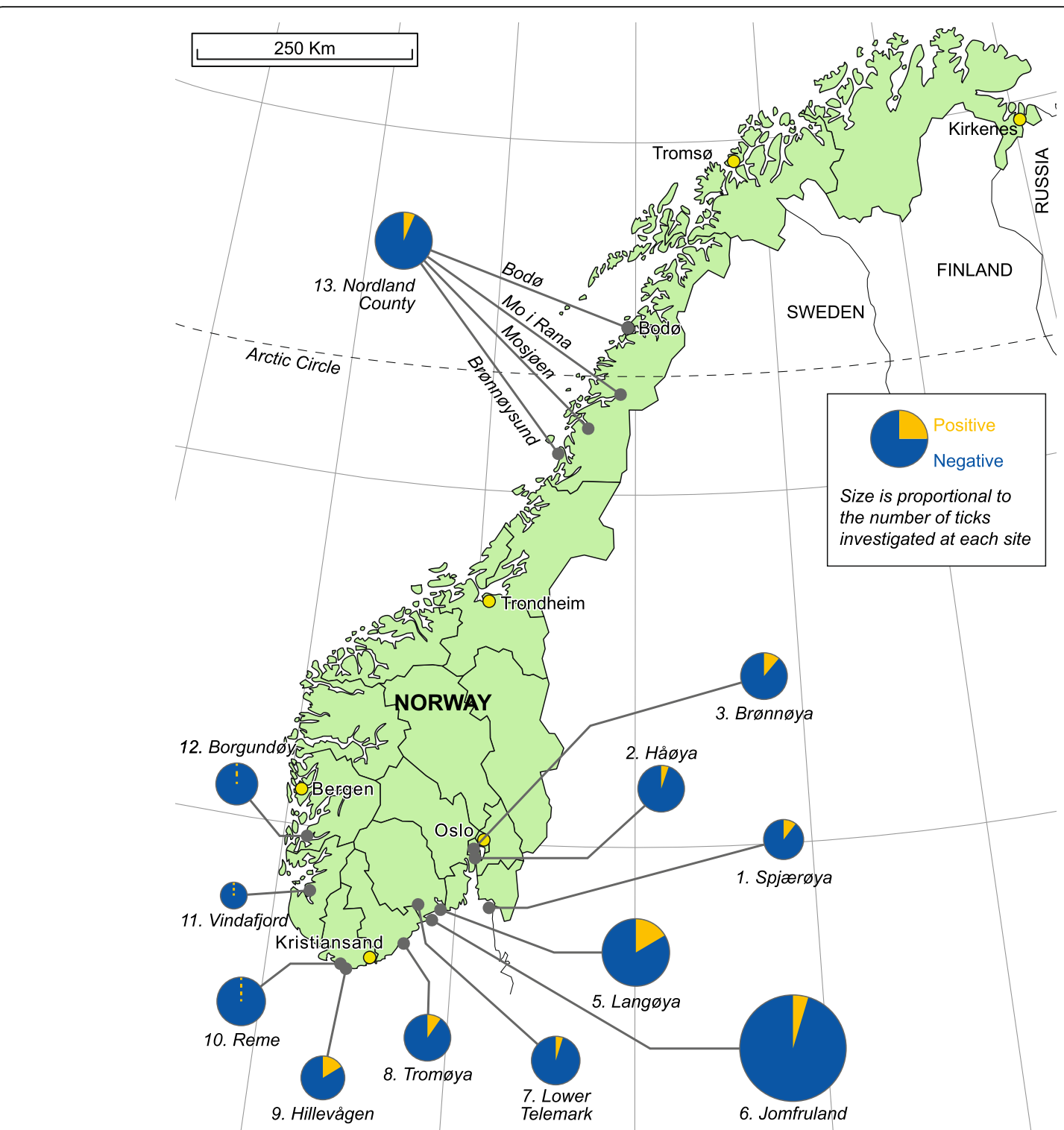

Fig. 4 Map of Norway showing collection locations and the proportion of adult and nymphal ticks positive for Ca. N. mikurensis at each location. Location numbers correspond to location numbers in Table 5. The areas of the pie charts are proportional to the number of ticks. Collection 4 is not included as it includes only larvae. The locality is the same as collection 5

Table 4 Spiking test for PCR inhibition in negative samples

\begin{tabular}{lllll}
\hline $\begin{array}{l}\text { Extraction } \\
\text { method }\end{array}$ & $N$ & Non-inhibitory & $\begin{array}{l}\text { Partially } \\
\text { inhibitory }\end{array}$ & $\begin{array}{l}\text { Completely } \\
\text { inhibitory }\end{array}$ \\
\hline 1 & 9 & 8 & 1 & 0 \\
2 & 15 & 14 & 0 & 1 \\
3 & 9 & 2 & 6 & 1 \\
4 & 9 & 2 & 2 & 5 \\
\hline
\end{tabular}

This, and the fact that the other three samples were negative suggest that the apparent positive result was an experimental artefact rather than actual cross-reaction with M. mitochondrii. However, we cannot entirely exclude the possibility that the cross-reaction is to a different $M$. mitochondrii gene as yet unsequenced. Attempts to sequence the PCR product were not successful.

Our results indicate that the SYBR-green PCR reaction alone is too unspecific to definitively distinguish $C a$. N. mikurensis from Ehrlichia species, or, by inference, other species of Neoehrlichia. This may in part be due to the high primer concentration used $(800 \mathrm{nM})$; equally good results may be obtained with $300 \mathrm{nM}$ and this is 
Table 5 Confirmation testing for ticks positive by SYBR-green PCR

\begin{tabular}{llllc}
\hline Collection & Location & $\begin{array}{l}\text { Total Pos } \\
\text { (SYBR-green) }\end{array}$ & $\begin{array}{l}\text { Confirmed } \\
\text { by probe }\end{array}$ & $\begin{array}{l}\text { Confirmed by } \\
\text { sequencing }\end{array}$ \\
\hline 1 & Spjærøy & $7 / 67$ & NT & \\
2 & Håøya & $5 / 95$ & $4 / 4$ & \\
3 & Brønnøya & $11 / 92$ & NT & \\
5 & Langøya & $32 / 194$ & $18 / 18$ & $3 / 3$ \\
6 & Jomfruland & $23 / 495$ & $20 / 23$ & $2 / 2$ \\
7 & Lower Telemark & $5 / 103$ & $3 / 3$ & \\
8 & Tromøya & $9 / 95$ & $1 / 1$ & \\
9 & Hillevåg & $13 / 80$ & $11 / 11$ & $7 / 7$ \\
10 & Reme & $0 / 101$ & $\mathrm{NA}$ & \\
11 & Vindafjord & $0 / 29$ & $\mathrm{NA}$ & \\
12 & Stord & $0 / 73$ & $\mathrm{NA}$ & \\
13 & Nordland & $9 / 139$ & $5 / 5$ & $3 / 3$ \\
All & - & $125 / 1561$ & $62 / 65$ & $15 / 15$ \\
\hline
\end{tabular}

NA: not applicable; no ticks were positive. NT: not tested; no material was available for confirmation

the concentration we now use. Tm analysis may help to constrain results, but we have found that this may vary by as much as $1.9^{\circ} \mathrm{C}$ for identical sequences unless conditions are carefully controlled. Tm analysis would correctly flag Ehrlichia muris $(\mathrm{Tm}=76.1)$ as a crossreaction, but not E. chaffeensis, whose $\mathrm{Tm}$ (73.9) is within the normal range for $\mathrm{Ca}$. N. mikurensis. However, these species are not known to occur in Northern Europe $[1,2]$.

In this study we have accepted the full range of observed Tm values (71.7-75) as positive, but our experience suggests that results at the extreme ends of this range $(<72.5$ or $>74.5)$ should be regarded as potential cross-reactions or artefacts. Thus, confirmation of results with the TaqMan MGB probe and/or sequencing is desirable. In this study all of 15 samples sequenced and 62/65 samples tested with the probe were confirmed. This indicates that false positives represent only a minor component of our results and do not significantly bias our prevalence estimates. The three unconfirmed samples had high $\mathrm{Cq}$ values and we were unable to reproduce the original positive SYBR-green PCR result; it is possible that the amount of DNA remaining was not sufficient to generate a positive result.

Andersson et al. [12] have developed a real time PCR targeting another segment of the groEL gene of $\mathrm{Ca}$. N. mikurensis. They found their PCR to be more sensitive than nested PCR targeting $16 \mathrm{~S}$ rDNA and reported a prevalence in ticks in southern Sweden of 6\%, which is close to that reported in this study. Vayssier-Taussat et al. [27] also describe a groEL real time PCR for Ca. N. mikurensis, although no sensitivity data are reported.
Our results extend knowledge of the prevalence of $\mathrm{Ca}$. $\mathrm{N}$. mikurensis to the northwestern limits of $I$. ricinus distribution and show that $\mathrm{Ca}$. N. mikurensis is prevalent in I. ricinus throughout most of its range in Norway up to its northern limit, which is currently close to the Arctic Circle. A recent, more detailed study in the latter region confirms this [43]. Our results also confirm previous findings of $\mathrm{Ca}$. N. mikurensis (then referred to as 'Ehrlichia-like organism') in ticks collected from southeastern Norway in 1999 [2]. Our findings are also consistent with the presence of $\mathrm{Ca}$. N. mikurensis in ticks and wild rodents in neighboring Sweden $[12,20]$ and its apparently pan-European distribution [26]. The sequence variant found in this study matches variants that have been found in southern (JQ669946), eastern (KF312363) and northern Europe (LC167302) in mammals (KR912350), ticks (KF312363), and humans (EU810406) [9].

The overall prevalence in nymphs and adults was $6.5 \%$. Where $C a$. N. mikurensis was detected, the observed prevalence varied from location to location (5$16 \%)$. However, this study was designed to investigate the distribution of $\mathrm{Ca}$. N. mikurensis in as many locations in Norway as possible using available material. As a prevalence study it has limitations: the nucleic acid extraction methods differed between locations; no attempt was made to control for failed extraction and there was evidence for PCR inhibition in more than half of the sample collections. For locations 7 and 13, the material used was reverse-transcribed total nucleic acid, a preparation chosen to allow detection of TBE-virus (an RNA virus) in the same material. As groEL is often strongly expressed, reverse transcription is expected to strengthen the PCR signal as both DNA and reversetranscribed messenger RNA will be available for amplication. However, the mean $\mathrm{Cq}$ value for this material did not differ from that found for other methods (data not shown), possibly because the extraction volume was sixfold higher and the material thus represented a smaller proportion of the ticks' DNA. False negative results and methodological biases are therefore possible and the local and overall prevalence estimates must be considered preliminary. Accurate prevalence estimates will require the use of standardised extraction methods and controls against inhibition and failed extraction.

In three locations no $\mathrm{Ca}$. N. mikurensis was detected at all. These locations were all on or near the Western Seaboard and sampled in August 2000. PCR inhibition is not a major issue for these samples and nor is degradation, as A. phagocytophilum was successfully detected in the same samples in experiments run concurrently with this study (data not shown) using an A. phagocytophilum-specific real time PCR method [44] that uses the same PCR buffers and which amplifies a target of similar 
size to that in the present assay. Thus, we conclude that either $\mathrm{Ca}$. N. mikurensis is locally scarce, or the ticks were collected at a point of time when $\mathrm{Ca}$. N. mikurensis prevalence was low. Seasonal variations in $\mathrm{Ca}$. N. mikurensis prevalence between 16\% in May and 2\% in June have been observed at location 5 (Fig. 1) [2]. This variation was paralleled by Borrelia burgdorferi sensu lato. Similar findings for B. burgdorferi sensu lato have been reported by Mysterud et al. [45].

Ca. N. mikurensis was not found in larvae (0/123), even though the larvae were collected in a highprevalence area (location 5, Langøya) where $C a . \mathrm{N}$. mikurensis was detected in females the previous year. This result is in agreement with previous findings using real time PCR [11], and suggests that transovarial transmission of $\mathrm{Ca}$. N. mikurensis is uncommon or absent, although conflicting results using nested PCR have been reported by Derdakova et al. [15] who found $C a$. N. mikurensis in four of ten larvae.

In contrast to other tick-borne pathogens, such as TBE-virus [46] and Borrelia [47], the prevalence of $\mathrm{Ca}$. $\mathrm{N}$. mikurensis was not greater in adults than in nymphs. This suggests that $I$. ricinus ticks predominantly acquire $C a$. N. mikurensis during their first blood meal and is consistent with small rodents, which are predominantly parasitized by larvae, being the main reservoir hosts for Ca. N. mikurensis $[22,26]$.

Our findings show that $\mathrm{Ca}$. N. mikurensis is widespread in Norway, with a mean prevalence of $6.5 \%$, making it the second most prevalent tick-borne pathogen after Borrelia afzelii [2,37]. Ca. N. mikurensis has been recently detected in clinical specimens [48] and the first case of human neoehrlichiosis in Norway was recently reported [49].

\section{Abbreviations}

Cq: Quantitation cycle. Fractional PCR cycle where an amplification curve crosses a threshold line. Also called Ct; GU: Genomic units. Number of copies of a DNA molecule corresponding to a single copy of the genome; MGB: Minor groove binder. A proprietary modification to TaqMan probes which increases Tm; Tm: Melting temperature of a DNA duplex

\section{Acknowledgements}

The authors would like to thank Anne-Gry Allum, Linda Strand, Ellen Johanne Kleveland, Anne-Lene Lundsett, Pia Øistad and Katrine M. Paulsen for assistance with collecting ticks, and Anne-Lene Lundsett and Rikke Rollum for extraction of DNA. We further gratefully acknowledge the expert services of Rod Wolstenholme in the preparation of Fig. 4. We would also like to thank Ulrike Munderloh and Leo Schouls for providing us with Ehrlichia and Anaplasma DNA.

\section{Authors' contributions}

The study was conceived, coordinated and supervised by AJ, who also designed the PCR test, contributed to laboratory work, reviewed and supplemented the data analyses and wrote the manuscript. $\mathrm{KJ}$ collected and analyzed the material from location 6. BNP performed the sequence analysis and supplementary laboratory analyses. All other experimental work and data analyses, except DNA extraction, was done by CR. ÅA, AS, $\mathrm{KSE}, \mathrm{HHL}, \mathrm{VK}, \mathrm{SS}, \mathrm{DH}, \mathrm{AJ}$ and BEK made major contributions to collection and processing of ticks. All authors reviewed the manuscript. All authors read and approved the final manuscript.

\section{Funding}

This study was partly funded by the Interreg IV A Program (the ScandTick project, grant no. 167226), the Interreg V Program (the ScandTick Innovation project, grant no. 20200422. The authors also acknowledge the support of Helse-Nord HF, and the Scandinavian Society for Antimicrobial Chemotherapy. The funding bodies did not influence any part of the study.

\section{Availability of data and materials}

Data sharing is not applicable to this article as no datasets were generated or analysed during the current study.

Ethics approval and consent to participate

Not applicable

Consent for publication

Not applicable

\section{Competing interests}

The authors declare that they have no competing interests.

\section{Author details}

${ }^{1}$ Department of Natural Science and Environmental Health, University of South-Eastern Norway, Bø, Norway. ${ }^{2}$ Present address: Nittedal Municipal Water and Drainage Authority, Nittedal, Norway. ${ }^{3}$ Present address: Telemark Trust Hospital, Section for Pathology, Skien, Norway. ${ }^{4}$ Department of Virology, Norwegian Institute of Public Health, Oslo, Norway. ${ }^{5}$ Department of Pest Control, Norwegian Institute of Public Health, Oslo, Norway. ${ }^{6}$ Department of Engineering and Science, University of Agder, Kristiansand, Norway. ${ }^{7}$ Sørlandet Trust Hospital Research Unit, Kristiansand, Norway. ${ }^{8}$ Department of Production Animal Clinical Sciences, Norwegian University of Life Sciences, Sandnes, Norway. ${ }^{9}$ Department of Microbiology and Infection Control, University Hospital of North Norway, Troms $\varnothing$, Norway. ${ }^{10}$ Department of Process, Energy, and Environmental Technology, University of South-Eastern Norway, Porsgrunn, Norway.

Received: 27 June 2018 Accepted: 31 May 2019

Published online: 28 August 2019

\section{References}

1. Schouls LM, van de Pol I, Sjoerd GT, Rijpkema GT, Schot CS. Detection and identification of Ehrlichia, Borrelia burgdorferi sensu lato and Bartonella species in Dutch Ixodes ricinus ticks. J Clin Microbiol. 1999;37:2215-22.

2. Jenkins A, Kristiansen BE, Allum AG, Aakre RK, Strand L, Kleveland EJ, van de Pol I, Schouls L. Borrelia burgdorferi sensu lato and Ehrlichia spp. in Ixodes ticks from southern Norway. J Clin Microbiol. 2001;39:3666-71.

3. Kawahara M, Rikihisa Y, Isogai E, Takahashi M, Misumi H, Suto C, Shibata S, Zhang C, Tsuji M. Ultrastructure and phylogenetic analysis of 'Candidatus Neoehrlichia mikurensis' in the family Anaplasmataceae, isolated from wild rats and found in Ixodes ovatus ticks. Int J Syst Evol Microbiol. 2004;54:1837-43.

4. Dumler JS, Barbet AF, Bekker CP, Dasch GA, Palmer GH, Ray SC, Rikihisa Y, Rurangirwa FR. Reorganization of genera in the families Rickettsiaceae and Anaplasmataceae in the order Rickettsiales: unification of some species of Ehrlichia with Anaplasma, Cowdria with Ehrlichia and Ehrlichia with Neorickettsia, descriptions of six new species combinations and designation of Ehrlichia equi and 'HGE agent' as subjective synonyms of Ehrlichia phagocytophila. Int J Syst Evol Microbiol. 2001;51:2145-65.

5. Welinder-Olsson C, Kjellin E, Vaht K, Jacobsson S, Wennerås C. First case of human "Candidatus Neoehrlichia mikurensis" infection in a febrile patient with chronic lymphocytic leukemia. J Clin Microbiol. 2010;48:1956-9.

6. Fehr JS, Bloemberg GV, Ritter C, Hombach M, Lüscher T, Keller PM. Septicemia caused by tick-borne Bacterial Pathogen Candidatus Neoehrlichia mikurensis. Emerg Infect Dis. 16:1127-9.

7. Grankvist A, Andersson P, Mattsson M, Sender M, Vaht K, Höper L, Sakiniene E, Trysberg E, Stenson M, Fehr J, Pekova S, Bogdan C, Bloemberg G, Wennerås C. Infections with the tick-borne bacterium "Candidatus Neoehrlichia mikurensis" mimic noninfectious conditions in patients with B cell malignancies or autoimmune diseases. Clin Infect Dis. 2014;58:1716-22. 
8. Li H, Jiang JF, Liu W, Zheng YC, Huo QB, Tang K, Zuo SY, Liu K, Jiang BG, Yang H, Cao WC. Human infection with Candidatus Neoehrlichia mikurensis. China Emerg Infect Dis. 2012;18:1636-9.

9. Welc-Falẹciak R, Siński E, Kowalec M, Zajkowska J, Pancewicz SA. Asymptomatic "Candidatus Neoehrlichia mikurensis" infections in immunocompetent humans. J Clin Microbiol. 2014;52:3072-4.

10. Palomar A, Garcia-Ávarez L, Santibáñez S, Portillo A, Oteo JA. Detection of tick-borne Candidatus Neoehrlichia mikurensis and Anaplasma phagocytophilum in Spain in 2013. Parasit Vectors. 2014;7:57.

11. Jahfari S, Fonville M, Hengeveld P, Reusken C, Scholte EJ, Takken W, Heyman P, Medlock JM, Heylen D, Kleve J, Sprong H. Prevalence of Neoehrlichia mikurensis in ticks and rodents from north-West Europe. Parasit Vectors. 2012;5:74

12. Andersson M, Bartkova S, Lindestad O, Råberg L. Co-infection with Candidatus Neoehrlichia mikurensis and Borrelia afzelii in Ixodes ricinus ticks in southern Sweden. Vector-Borne Zoonotic Dis. 2013;13:438-42.

13. Maurer FP, Keller PM, Beuret C, Joha C, Achermann Y, Gubler J, Bircher D, Karrer U, Fehr J, Zimmerli L, Bloemberg G. Close association of human neoehrlichiosis and tick populations carrying "Candidatus Neoehrlichia mikurensis" in eastern Switzerland. J Clin Microbiol. 2013;51:169-76.

14. Fertner M, Molbak L, Boye Pihl T, Fomsgaard A, Bodker R. First detection of tick-borne Candidatus Neoehrlichia mikurensis in Denmark 2011. Euro Surveill. 2012;17:20096.

15. Derdáková $M$, Václav $R$, Pangrácova-Blanárova L, Selyemová $D$, Koci J, Walder G, pitalská E. Candidatus Neoehrlichia mikurensis and its $\mathrm{CO}^{-}$ circulation with Anaplasma phagocytophilum in Ixodes ricinus ticks across ecologically different habitats of Central Europe. Parasit Vectors. 2014;7:160.

16. Otranto D, Dantas-Torres F, Giannelli A, Latrofa MS, Cascio A, Cazzin S, Ravagnan S, Montarsi F, Zanzani SA, Manfredi MT, Capelli G. Ticks infesting humans in Italy and associated pathogens. Parasit Vectors. 2014;7:328

17. Szekeres S, Coipan EC, Rigó K, Majoros G, Jahfari S, Sprong H, Földvári G. Candidatus Neoehrlichia mikurensis and Anaplasma phagocytophilum in natural rodent and tick communities in southern Hungary. Ticks Tick Borne Dis. 2015;6:111-6.

18. Richter D, Matuschka FR. "Candidatus Neoehrlichia mikurensis," Anaplasma phagocytophilum, and Lyme disease spirochetes in questing European vector ticks and in feeding ticks removed from people. J Clin Microbiol. 2012:50:943-7.

19. Rar VA, Livanova NN, Panov W, Doroschenko EK, Pukhovskaya NM, Vysochina NP, Ivanov LI. Genetic diversity of Anaplasma and Ehrlichia in the Asian part of Russia. Ticks Tick Borne Dis. 2010;1:57-65.

20. Andersen M, Råberg L. Wild Rodents and Novel Human Pathogen Candidatus Neoehrlichia mikurensis, Southern Sweden. Emerging Infect Dis. 2011;17:1716-8.

21. Obiegala A, Pfeffer M, Pfister K, Tiedemann T, Thiel C, Balling A, Karnath C, Woll D, Silaghi C. Candidatus Neoehrlichia mikurensis and Anaplasma phagocytophilum: prevalences and investigations on a new transmission path in small mammals. Parasit Vectors. 2014;7:563.

22. Burri C, Schumann O, Scumann C, Gern L. Are Apodemus spp mice and Myodes glareolus reservoirs for Borrelia miyamotoi, Candidatus Neoehrlichia mikurensis, Rickettsia helvetica, R. monacensis and Anaplasma phagocytophilum? Ticks Tick Borne Dis. 2014;5:245-251.

23. Silaghi C, Woll D, Mahling M, Pfister K, Pfeffer M. Candidatus Neoehrlichia mikurensis in rodents in an area with sympatric existence of the hard ticks Ixodes ricinus and Dermacentor reticulatus. Parasit Vectors. 2012:5:285.

24. Diniz PPVP, Schultz BS, Hartmann K, Breitschwerdt EB. Candidatus Neoehrlichia mikurensis infection in a dog from Germany. J Clin Microbiol. 2011;49: 2059-62.

25. Földvári G, Jahfari S, Rigó K, Jablonsky M, Szekeres S, Majoros G, Tóth M, Molnár V, Coipan EC, Sprong H. Candidatus Neoehrlichia mikurensis and Anaplasma phagocytophilum in urban hedgehogs. Emerg Infect Dis. 2014;20:496-8.

26. Silaghi C, Beck R, Oteo JA, Pfeffer M, Sprong H. Neoehrlichiosis: an emerging tick-borne zoonosis caused by Candidatus Neoehrlichia mikurensis. Exp Appl Acarol. 2016:68:279-97.

27. Vayssier-Taussat M, Moutailler A, Michelet L, Devillers E, Bonnet S, Cheval J, Hébert C, Eloit M. Next generation sequencing uncovers unexpected bacterial pathogens in ticks in Western Europe. PLoS One. 2013;8:e81349.

28. Tambs-Lyche $\mathrm{H}$. Ixodes ricinus og piroplasmosen i Norge. Norsk Veterinærtidskrift. 1943;55:401-41 449-506.

29. Mehl R. The distribution and host relations of Norwegian ticks (Acari, Ixodes). Fauna Norvegica. 1983;30:46-51.
30. Hvidsten D, Stuen S, Jenkins A, Dienus O, Olsen RS, Kristiansen BE, Mehl R, Matussek A. Ixodes ricinus and Borrelia prevalence at the Arctic circle in Norway. Ticks Tickborne Dis. 2013;5:107-12.

31. Soleng A, Edgar KS, Paulsen KM, Pedersen BN, Okbaldet YB, Skjetne IEB, Gurung D, Vikse R, Andreassen Å. Distribution of Ixodes ricinus ticks and prevalence of tick-borne encephalitis virus in questing ticks in the Arctic circle region of northern Norway. Ticks and Tick-Borne Diseases. 2018;9:97-103.

32. Hillyard PD. Ticks of north-West Europe (synopses of the British Fauna). Shrewsbury: Field Studies Council; 1996.

33. Jenkins A, Hvidsten D, Matussek A, Lindgren PE, Stuen S, Kristiansen BE. Borrelia burgdorferi sensu lato in Ixodes ricinus ticks from Norway: evaluation of a PCR test targeting the chromosomal flaB gene. Exp Appl Acarol. 2012; 58:431-9.

34. Guy EC, Stanek G. Detection of Borrelia burgdorferi in patients with Lyme disease by the polymerase chain reaction. J Clin Pathol. 1991:44:103-10.

35. Morán-Cadenas F, Schneider H, Lommano E, Burri C, Moret J, Gern L. A comparison of two DNA extraction approaches in the detection of Borrelia burgdorferi Sensu Lato from live Ixodes ricinus ticks by PCR and reverse line blotting. Vector-Borne and Zoonotic Diseases. 2008;7:555-62.

36. Halos L, Jamal T, Vial L, Maillard R, Suau A, Le Menach A, Boulouis HJ. Determination of an efficient and reliable method for DNA extraction from ticks. Vet Res. 2004;35:709-13.

37. Kjelland V, Paulsen KM, Rollum R, Jenkins A, Stuen S, Soleng A, Edgar KS, Lindstedt HH, Vaino K, Gibory M, Andreassen Å. Tick-borne encephalitis virus (TBEV), Borrelia burgdorferi sensu lato, Borrelia miyamotoi, Anaplasma phagocytophilum and Candidatus Neoerlichia mikurensis in Ixodes ricinus ticks collected from recreational islands in Southern Norway. Ticks Tick Borne Dis. 2018; In Press.

38. Raasok C. Candidatus Neoehrlichia mikurensis i Ixodes ricinus i Norge. MSC Thesis, Høgskolen I Telemark; 2015.

39. Jensen K. Flåttmidler og flåttbårne patogener. MSc Thesis. University College of Southeast Norway; 2016.

40. Lundsett A. Flåtten Ixodes ricinus som sykdomsvektor I Sør-Norge. Hovedfagsoppgave, Høgskolen i Telemark; 2004

41. Ang D, Ziegelhoffer T, Maddock A, Zeilstra-Ryalls J, Georgopoulos C, Fayet O, Liberek K, Skowyra D, Marszalek J, Osipiuk J, Wojtkowiak S. The biological role of the universally Conserved E. coli heat shock proteins. In: Heat shock. Berlin Heidelberg: Springer; 1991. p. 45-53.

42. Fleiss JL. Statistical methods for rates and proportions. New York: Wiley; 1981.

43. Larsson C, Hvidsten D, Stuen S, Henningsson AJ, Wilhelmsson P. "Candidatus Neoehrlichia mikurensis" in Ixodes ricinus ticks collected near the Arctic circle in Norway. Parasit Vectors. 2018;11:260.

44. Henningsson AJ, Hvidsten D, Kristiansen BE, Matussek A, Stuen S, Jenkins A. Anaplasma phagocytophilum in Ixodes ricinus ticks from Norway: evaluation of a real-time PCR assay targeting the Anaplasma citrate synthase ( $\mathrm{g} / \mathrm{tA})$ gene. BMC Microbiol. 2015;15:153.

45. Mysterud A, Easterday WR, Qviller L, Viljugrein H, Ytrehus B. Spatial and seasonal variation in the prevalence of Anaplasma phagocytophilum and Borrelia burgdorferi sensu lato in questing Ixodes ricinus ticks in Norway. Parasit Vectors. 2013:20:187.

46. Pettersson JH, Golovljova I, Vene S, Jaenson TG. Prevalence of tick-borne encephalitis virus in Ixodes ricinus ticks in northern Europe with particular reference to southern Sweden. Parasit Vectors. 2014;7:102.

47. Rauter C, Hartung T. Prevalence of Borrelia burgdorferi Sensu Lato Genospecies in Ixodes ricinus ticks in Europe: a Metaanalysis. Appl Environ Microbiol. 2005;71:7203-16.

48. Quarsten H, Grankvist A, Høyvoll L, Myre IB, Skarpaas T, Kjelland V, Wennerås C, Noraas S. Candidatus Neoehrlichia mikurensis and Borrelia burgdorferi sensu lato detected in the blood of Norwegian patients with erythema migrans. Ticks Tickborne Dis. 2017:8:715-20.

49. Frivik JO, Noraas S, Grankvist A, Wennerås C, Quarsten H. A man in his sixties from southern Norway with intermittent fever. Tidskr Nor Legeforen. 2017;137:23-4

\section{Publisher's Note}

Springer Nature remains neutral with regard to jurisdictional claims in published maps and institutional affiliations. 